Eur. J. Biochem. 188, 439-445 (1990)

\title{
Structure and biosynthesis of the signal-sequence receptor
}

\author{
Siegfried PREHN ${ }^{1}$, Joachim HERZ ${ }^{2}$, Enno HARTMANN ${ }^{3}$, Teymuras V. KURZCHALIA ${ }^{3}$, Rainer FRANK ${ }^{2}$, Karin ROEMISCH $^{2}$, \\ Bernhard DOBBERSTEIN ${ }^{2}$ and Tom A. RAPOPORT ${ }^{3}$ \\ 1 Institut für Biochemie der Humboldt-Universität zu Berlin, Berlin, German Democratic Republic \\ 2 Europäisches Molekularbiologie Laboratorium, Heidelberg, Federal Republic of Germany \\ 3 Zentralinstitut für Molekularbiologie der Akademie der Wissenschaften der DDR, Berlin-Buch, German Democratic Republic
}

(Received July 28, 1989) - EJB 890939

The signal-sequence receptor (SSR) has previously been shown to be a component of the environment which nascent polypeptides meet on passage through the endoplasmic reticulum (ER) membrane. We report here on the primary structure of the SSR as deduced from cDNA clones and from direct protein sequencing. The glycoprotein is synthesized with a cleavable amino-terminal signal sequence and contains only one classical membrane-spanning segment. Its insertion into the ER membrane during biosynthesis depends on the function of the signal-recognition particle. SSR shows a remarkable charge distribution with the amino terminus being highly negatively charged, and the cytoplasmic carboxyl terminus positively charged. The SSR can be phosphorylated in its cytoplasmic tail both in intact cells and in a cell-free system, suggesting a regulation of its function. The localization of the protein in the ER membrane was confirmed by immunofluorescence microscopy.

Protein translocation across the endoplasmic reticulum membrane is initiated by an interaction of the signal sequence of the nascent polypeptide with the 54-kDa polypeptide component of the signal-recognition particle (SRP) [1-3]. Association with the membrane is mediated by the affinity of SRP for its receptor in the ER membrane, also called docking protein $[4,5]$, which has recently been shown to be a GTPbinding protein [6]. On interaction with its receptor, the SRP is released from both the ribosome [7] and from the signal sequence [8] and the latter is transferred into close proximity of an integral, glycosylated membrane protein of molecular mass $\approx 34 \mathrm{kDa}$, called the signal-sequence receptor [9]. Identification of the SSR was based on a photocrosslinking approach whereby a photoreactive lysine derivative was introduced into the signal sequence of nascent preprolactin and crosslinking to the SSR was induced by irradiation [2,9]. Using the same technique, it has been recently shown that not only the signal sequence but also the succeeding part of nascent proprolactin is located in proximity to the SSR during translocation [10]. This result indicates that the SSR is a component of the environment which nascent polypeptide chains meet on passage through the ER membrane. SSR may be a constituent of a postulated translocation complex through which the nascent chain traverses the membrane.

On the basis of the properties of the SSR as deduced from crosslinking experiments, we have purified a $34-\mathrm{kDa}$ integral

Correspondence to S. Prehn, Institut für Biochemie der HumboldtUniversität zu Berlin, Hessische Strasse 3-4, DDR1040 Berlin, German Democratic Republic

Abbreviations. SSR, signal-sequence receptor; ER, endoplasmic reticulum; SRP, signal-recognition particle; MDCK, Madin Darby canine kidney; Bz, benzoyl; SSC, $0.15 \mathrm{M} \mathrm{NaCl} / 15 \mathrm{mM}$ trisodium citrate, $\mathrm{pH} 7.0 ; \mathrm{K}-\mathrm{RM}$, salt-washed microsomes.

Note. The novel nucleotide sequence data published here has been deposited with the EMBL sequence data banks and is available under accession number X51367. membrane glycoprotein from dog pancreatic microsomes [11]. Identity with the SSR is indicated by the fact that antibodies to the purified protein recognize the crosslinked products [10]. The SSR is present in the ER membrane of various types of cells of different species in excess over membrane-bound ribosomes [10], in keeping with its assumed role as a constituent of the translocation complex. The protein appears to be essential for translocation since antibodies directed against it and $F_{a b}$ fragments prepared from the antibodies inhibit the translocation of several secretory proteins in vitro [11].

It is obviously of great interest to obtain structural information on the SSR. Is it a tunnel protein similar in structure to the ion channels or electron transporters (for review, see [12])? Given the fact that macromolecules should pass through the postulated translocation complex, one may expect completely different features. Indeed, we report here that the primary structure of the SSR does not contain multiple membrane-spanning segments with amphipathic helical character. The protein has only one classical membrane-spanning segment and displays a remarkable charge distribution with the $\mathrm{N}$-terminus highly negatively charged and the $\mathrm{C}$-terminus positively charged. Insertion of the SSR into the ER membrane during biosynthesis depends on the function of the SRP. We have also found that the SSR is phosphorylated at its cytoplasmic tail.

\section{MATERIALS AND METHODS}

\section{Amino acid sequencing}

SSR was purified from canine microsomes extracted with alkali by concanavalin-A - Sepharose chromatography as described [11]. The eluted glycoproteins were separated in $10 \%$ SDS/polyacrylamide gels, the proteins were electroblotted onto nitrocellulose and stained with Ponceau S. Sequencing of tryptic peptides of the SSR was carried out according to Aebersold et al. [13]. CNBr-peptides of gel-eluted 
SSR were separated by HPLC and subjected to automated sequencing.

\section{cDNA cloning, screening and nucleotide sequencing}

A cDNA library was prepared from cytoplasmic poly(A)rich RNA, isolated from MDCK (Madin Darby canine kidney) cells, essentially as described by Haymerle et al. [14]. The double-stranded cDNA was ligated to adaptors and cloned into the BamHI site of the bacterial expression vector pTEX. pTEX is a derivative of the $\mathrm{pEX} / \mathrm{pUEX}$ vector family (J. Herz et al., unpublished results).

Hydridization screening of colonies was carried out according to Maniatis et al. [15] with the following two oligonucleotides: $\quad 5^{\prime}$-AT(A/G)TA(A/G)AA(T/C)TG(A/G)TA(A/G)TC(T/C)TG-3' and 5'-TT(A/G)TTNGCNGG(A/ G)AA(A/G)TC(T/C)TC-3' (N indicates that all four bases were inserted at that position), corresponding to the peptides QDYQFYI and EDFPANN, respectively. The probes were end-labeled with $\left[\gamma_{-}{ }^{32} \mathrm{P}\right] \mathrm{ATP}$ and polynucleotide kinase and hybridized in $6 \times \mathrm{SSC}$ (SSC: $0.15 \mathrm{M} \mathrm{NaCl}, 15 \mathrm{mM}$ trisodium citrate, $\mathrm{pH} 7.0$ ) at $42^{\circ} \mathrm{C}$. Washing was carried out with $4 \times \mathrm{SSC}$ at $37^{\circ} \mathrm{C}$.

Immunoscreening with antibodies to the SSR [11] was carried out according to Stanley and Luzio [16] after growth of the colonies at $42^{\circ} \mathrm{C}$.

HindIII and PstI fragments of the positive clones were cloned into M13 mp18 and 19 and both DNA strands were sequenced by the Sanger method with sequenase (United States Biochemical, manufacturer's protocol). Some regions were analyzed by the use of internal oligonucleotide primers synthesized according to the already known sequence.

\section{Cell-free transcription/translation}

The insert of a SSR clone was cut out with the restriction enzyme NotI, the ends were filled in with Klenow enzyme and the DNA fragment cloned into the SmaI site of the vector pGEM2. In vitro transcription was carried out with T7-RNA polymerase as described by Melton et al. for SP6 polymerase [17]. Translation in a wheat germ cell-free system was performed with $\left[{ }^{35} \mathrm{~S}\right]$ methionine $(>50 \mathrm{TBq} / \mathrm{mmol})$ as labelled amino acid as described [8]. Salt-washed microsomes (K-RM) and SRP were isolated as described $[18,19]$ and added at final concentrations of $4 A_{280}$ unit/ml or $0.03 A_{260}$ unit $/ \mathrm{ml}$, respectively. The glycosylation competitor peptide Bz-AsnLeu-Thr-NH-Me [20] was used at a final concentration of $30 \mu \mathrm{M}$. Posttranslational proteolysis was carried out with $0.3 \mathrm{mg} / \mathrm{ml}$ proteinase $\mathrm{K}$ for $1 \mathrm{~h}$ at $0^{\circ} \mathrm{C}$. Where indicated, $0.3 \%$ Nonidet P-40 was added.

\section{Transient expression of SSR in $C V-1$ cells} and immunofluorescence microscopy

The insert of a SSR-clone was recloned into the vector pSVL51 [21] under a simian virus 40 promoter. CV-1 cells were transfected using the DEAE-Dextran method [22]. Cells were labelled overnight with $\left[{ }^{35}\right.$ S $]$ methionine $(7.4 \mathrm{MBq} / 10-\mathrm{cm}$ dish) two days after transfection. Lysis of the cells was carried out with a buffer containing $20 \mathrm{mM}$ Tris $/ \mathrm{HCl} \mathrm{pH} 7.5,150 \mathrm{mM}$

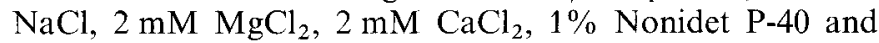
$1 \mathrm{mM}$ phenylmethylsulfonyl fluoride. Immunoprecipitation with antiserum to the SSR [11] was carried out as described using protein-A - Sepharose to collect the antigen - antibody complexes [9].
Indirect immunofluorescence microscopy was performed with antibodies against SSR and tetramethylrhodamineisothiocyanate-labelled second antibodies directed against rabbit immunoglobulin.

\section{Phosphorylation of the $S S R$}

For phosphorylation in intact cells, MDCK cells $\left(\approx 5 \times 10^{6}\right)$ were incubated with $\left[{ }^{32} \mathrm{P}\right]$ phosphate $(18.5 \mathrm{MBq} /$ $\mathrm{ml}$ ) for $2 \mathrm{~h}$ in medium lacking serum. The cells were lysed and the proteins subjected to immunoprecipitation with antiserum to SSR.

Cell-free phosphorylation was performed in a $25 \mu \mathrm{l}$ assay containing $20 \mathrm{mM}$ Hepes $/ \mathrm{KOH}, \mathrm{pH} 7.5,100 \mathrm{mM} \mathrm{NaCl}$, $2 \mathrm{mM} \mathrm{MgCl}_{2}$ and $0.2 \mathrm{MBq}$ of $\left[\gamma^{32} \mathrm{P}\right] \mathrm{ATP}$. One equivalent of microsomes was added. Where indicated wheat germ extract ( $\approx 10 \mu \mathrm{g}$ protein) and inhibitor of the cAMP-dependent protein kinase $(8 \mu \mathrm{g})$ were also added. Incubations were carried out at $0^{\circ} \mathrm{C}$ for $20 \mathrm{~min}$. For alkaline extraction, $150 \mu 10.15 \mathrm{M}$ $\mathrm{Na}_{2} \mathrm{CO}_{3}$ were added. After $10 \mathrm{~min}$ incubation in ice, the samples were centrifuged in a Beckman Airfuge for 10 min at $0.14 \mathrm{MPa}$. The pellets were dissolved in $2 \%$ SDS and analyzed by SDS gel electrophoresis according to Laemmli [23].

Wheat germ postribosomal supernatant was obtained from an extract by centrifugation at $100000 \times g_{a v}$ for $1 \mathrm{~h}$.

\section{Peptide antibodies and immunoblots}

Antibodies to a peptide comprising the C-terminal 15 amino acids of the SSR were raised in rabbits after coupling to keyhole-limpet hemocyanine with glutaraldehyde. Immunoblot analysis of electrophoretically separated microsomal proteins was carried out as described [11].

\section{RESULTS}

\section{Amino acid sequencing}

The 34-kDa protein (SSR) was isolated from canine microsomes as described previously [11]. Partial amino acid sequences were obtained from purified peptides obtained by cleavage of the SSR with trypsin or CNBr. The amino terminus of the protein could not be determined since it was found to be blocked.

The partial amino acid sequence obtained for the SSR is shown in parenthesis in Fig. 1 below the nucleotide sequence of the cDNA.

\section{cDNA cloning}

Two oligonucleotides were synthesized, the sequences of which were based on those of two of the tryptic peptides (see Materials and Methods). The probes were end-labelled and used to screen a MDCK-cell cDNA library cloned into the vector pTEX [14] (Herz et al., unpublished results).

MDCK cells have been derived from dog kidney and have been used previously to clone the SRP receptor [24]. The synthesis of SSR in these cells could be demonstrated by immunoprecipitation after metabolic labelling with $\left[{ }^{35} \mathrm{~S}\right]$ methionine (data not shown). The vector pTEX can also be used to screen with antibodies for the temperature-sensitive expression of a fusion between $\beta$-galactosidase and the desired protein.

Among approximately 150000 independent recombinants screened, 25 were found to hybridize with both oligonucleotide 


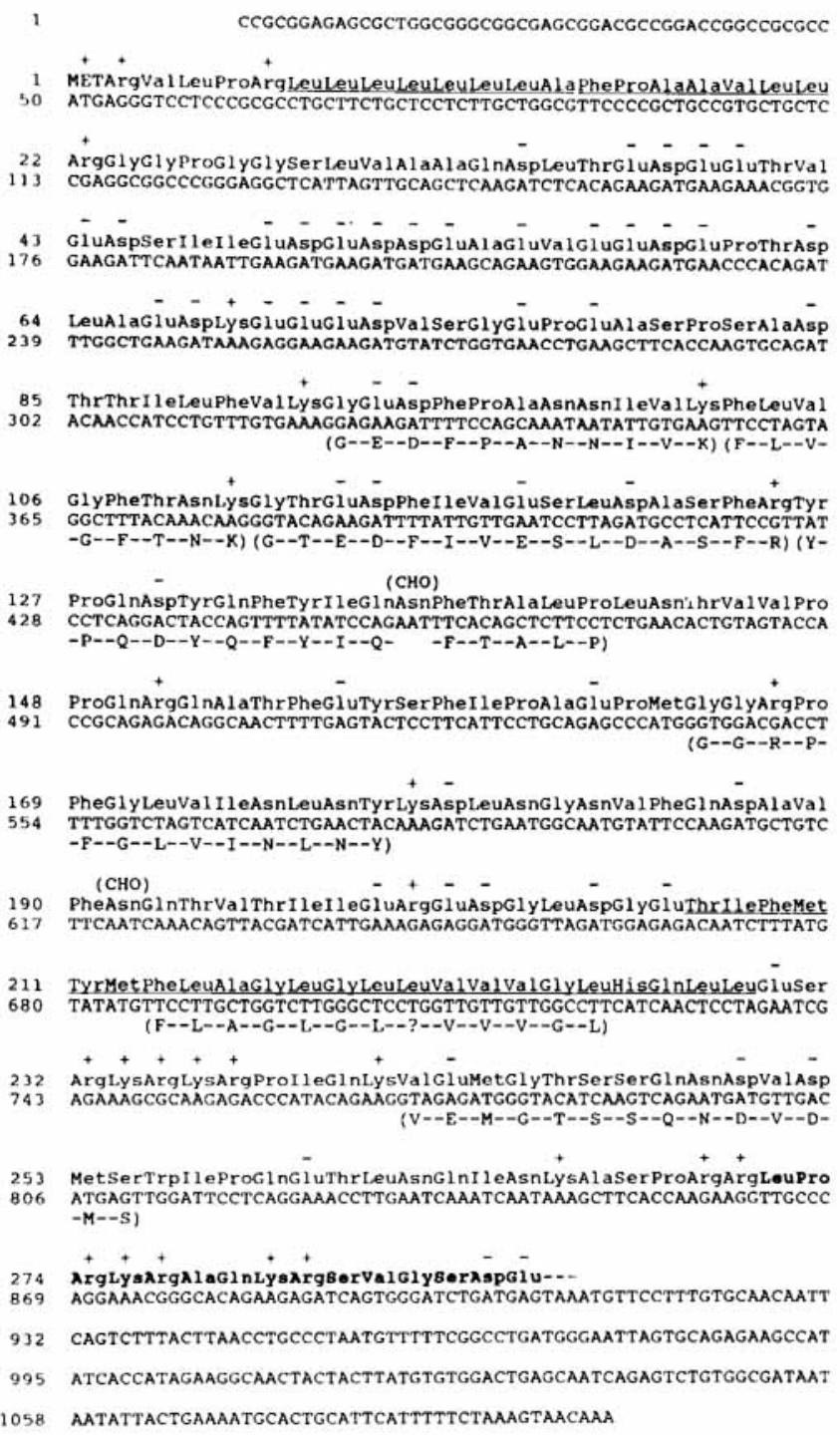

Fig. 1. Nucleotide and amino acid sequence of the SSR. The nucleotide sequence was determined from cloned cDNA. The amino acid sequence derived from it is shown above, and that determined directly is given below (given in parenthesis in the one-letter code). The sequence of a synthetic peptide against which antibodies were raised is given in bold face. Hydrophobic amino acid sequences are underlined. Potential glycosylation sites are indicated by $(\mathrm{CHO})$

probes. Except for two clones, the inserts all had a size of about $2 \mathrm{~kb}$ and contained the same sequence according to cross-hybridization data (not shown). The two exceptional clones had inserts of about $4 \mathrm{~kb}$ which were identical in sequence at their 5'-ends to the smaller clones. They may perhaps represent clones of nonspliced pre-mRNA. Among the positive clones with $\approx 2 \mathrm{~kb}$ inserts, two were found to express a fusion protein after temperature induction which reacted with antibodies to the 34-kDa SSR (data not shown). One of these clones was subcloned into M13 and sequenced. In addition, one of the $\approx 2-\mathrm{kb}$ clones that did not give an immunoreactive fusion protein was also sequenced. The nucleotide sequences were identical except for the number of bases at the extreme 5 '-untranslated terminus (Fig. 1 shows the sequence common to both clones).

The amino acid sequence derived from the nucleotide sequence is in good agreement with that directly determined (Fig. 1). All the peptides sequenced were found in the amino

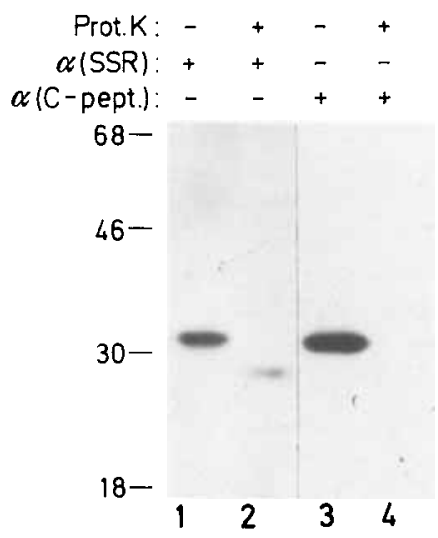

Fig. 2. Antibodies to a C-terminal peptide recognize a cytosolic domain of SSR. Microsomal membranes from dog pancreas (two equivalents) were either treated with proteinase $\mathrm{K}$ (Prot. $\mathrm{K} ; 0.1 \mathrm{mg} / \mathrm{ml}, 10 \mathrm{~min}$, $25^{\circ} \mathrm{C}$; lanes 2 and 4) or remained untreated (lanes 1 and 3). The proteins were analyzed after SDS/PAGE by immunoblotting with antibodies directed against intact SSR, $\alpha($ SSR $)$ [11] (lanes 1 and 2), or against a peptide comprising the C-terminal 15 amino acids, $\alpha(\mathrm{C}$ pept.; lanes 3 and 4 ; see Fig. 1). The numbers give the molecular mass of marker proteins

acid sequence derived from the cDNA clones. The calculated isoelectric point ( $\mathrm{pH} 4.1$ ) is in good aggreement with that determined experimentally [11].

Further proof that the correct protein has been cloned was obtained by producing antibodies to a synthetic peptide comprising the C-terminal 15 amino acids (indicated in bold face in Fig. 1). Imunoblots demonstrate that the antibodies recognize the SSR in microsomes (Fig. 2, lane 3). If microsomes were pretreated with a high concentration of protease, the reactivity was lost (Fig. 2, lane 4), whereas the antibodies against the intact SSR reacted with the protein fragment (cf. lanes 1 and 2). These data indicate that the epitope of the SSR recognized by the peptide antibodies is exposed to the cytosol.

The sequence upstream of the assumed initiator methionine is very similar to the consensus sequence (GCCGCC(A) G)CCATG) determined by Kozak [25] to be present at most sites of translation initiation in eukaryotic mRNA.

In order to provide additional proof that the clones contain the entire coding sequence of the SSR, the DNA was recloned under the simian virus 40 promoter and expressed in CV-1 cells. The cells were incubated with $\left[{ }^{35} \mathrm{~S}\right]$ methionine, lysed under non-denaturing conditions and the proteins subjected to immunoprecipitation with antibodies to the $34-\mathrm{kDa}$ SSR (Fig. 3). The overexpressed SSR had exactly the same size as the endogenous protein (Fig. 3, arrow, cf. lanes 1 and 2 with lane 3). A band of slightly slower mobility seen after overexpression presumably represents a precursor polypeptide from which the signal sequence has not yet been removed (see below). It should also be noted that two other polypeptides of lower and higher molecular mass were coimmunoprecipitated under these conditions (Fig. 3, see arrow head and bar). The smaller one appears to be identical with a recently discovered $\approx 22-\mathrm{kDa}$ protein that is tightly bound to the SSR (D. Goerlich et al., unpublished results); the nature of the larger protein is unclear as yet.

\section{Properties of the SSR sequence}

The amino acid sequence reveals two potential sites for $\mathrm{N}$ linked glycosylation (Fig. 1). According to the hydrophobicity 


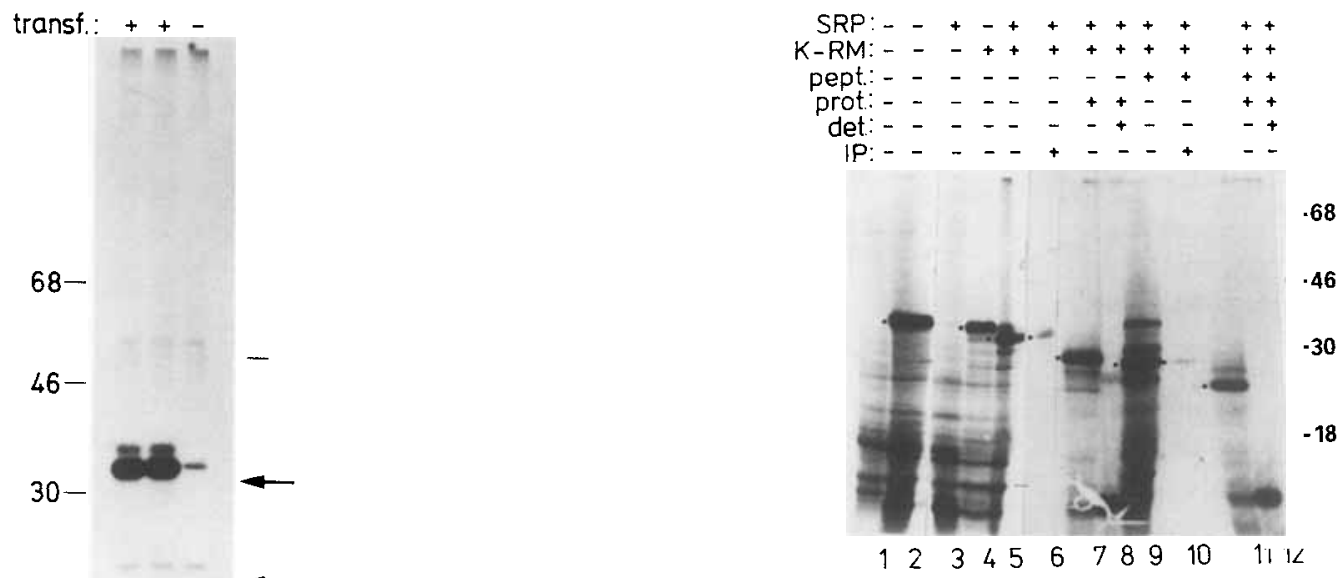

Fig. 4. In vitro insertion of SSR into microsomal membranes. RNA coding for the SSR was synthesized by in vitro transcription and translated in a wheat germ cell-free system (lanes 2-12). Sample 1 did not receive RNA. SRP, salt-washed canine microsomes (K-RM) and a peptide competitively inhibiting glycosylation (pept.) were added to the incubations as indicated. After translation, posttranslational proteolysis with proteinase $\mathrm{K}$ (prot.) was carried out in the presence or absence of detergent (det.) as indicated. The products were either analyzed directly by SDS/PAGE or after immunoprecipitation with SSR antibodies (IP, lanes 6 and 10). The dots indicate the bands of interest immunoprecipitation with SSR antibodies. The proteins were separated by SDS/PAGE and visualized by fluorography. Lanes 1 and 2 show the results of two independent experiments; lane 3 shows a control with nontransfected cells. The arrow indicates the position of the SSR, the arrow head and the bar that of two other polypeptides which were coprecipitated

scales of Kyte and Doolittle [26] and of Eisenberg et al. [27] there are two possible membrane-spanning segments, one close to the $\mathrm{N}$-terminus and one between residues 207 and 230. The latter domain is a classical membrane-anchor sequence. Its orientation must be such that the amino terminus faces the lumen of the ER and the carboxyl terminus the cytosol. This orientation is deduced from the position of the potential $N$-glycosylation sites (lumen of the ER) and from the fact that extensive proteolysis of microsomal membranes cleaves off about $7 \mathrm{kDa}$ from the SSR [11] which would correspond to the 56-amino-acid residues following the membranespanning segment. Furthermore, the data shown in Fig. 2 also demonstrate that the $\mathrm{C}$-terminal residues are accessible to proteolytic attack.

In order to test if the N-terminal hydrophobic segment represents a cleavable signal sequence, the cDNA was recloned into the pGEM vector under the T7-polymerase promoter and used in cell-free transcription/translation experiments (Fig. 4). A translation product of about $35 \mathrm{kDa}$ was obtained in the wheat germ system (Fig. 4, lane 2). If translation was carried out in the presence of SRP, the synthesis was severely inhibited (Fig. 4, lane 3). A similar translational inhibition by SRP has been observed for many other secretory and membrane proteins (for review, see Rapoport [28]). If the system was complemented by microsomal membranes depleted of SRP by extraction with high salt (K-RM), the inhibition was partially released and a band at $34 \mathrm{kDa}$, at the same position as natural SSR, was seen (Fig. 4, lane 5) which was in part immunoprecipitable (lane 6). K-RMs alone did not produce this band (Fig. 4, lane 4). If core glycosylation was prevented by addition of a competitor peptide [20], the main translation product had a size of about $30 \mathrm{kDa}$ (Fig. 4, lane 9); it was recognized by SSR antibodies (lane 10). The data indicate that

two carbohydrate chains, each contributing $\approx 2 \mathrm{kDa}$, are present in the 34-kDa protein. Whenever microsomes were present during translation, the product lost about $5-7 \mathrm{kDa}$ after treatment with protease (Fig. 4, lanes 7 and 11). If proteolysis was carried out in the presence of detergent, the proteins were totally degraded (Fig. 4, lanes 8 and 12). These results show that the SSR is integrated into the ER membrane with a cleavable signal peptide in a SRP-dependent fashion, that it spans the membrane with the second hydrophobic domain, and that it contains two carbohydrate chains.

The exact cleavage site of the signal peptidase remains unclear as yet since the amino terminal residue(s) of the mature protein could not be determined. Predictions are difficult since no site conforming to the $-1,-3$ rule [29] can be found. In any case, most if not all of the highly negatively charged region following the $\mathrm{N}$-terminal hydrophobic segment must be present in the mature protein to explain its low isoelectric point [11].

The charge distribution in the SSR sequence is indeed its most remarkable feature. The amino terminal region contains 23 negative charges in a segment of 35 residues, whereas the carboxyl terminal portion following the second hydrophobic domain is predominantly positively charged (Fig. 1).

\section{The SSR can be phosphorylated}

Since the function of the SSR in the translocation process may be modulated under certain conditions, we have tested the possibility that it is phosphorylated. MDCK cells were incubated with radioactive inorganic phosphate, lysed and the proteins subjected to immunoprecipitation with antibodies to the SSR (Fig. 5). Indeed a labelled band at the expected position was observed (Fig. 5, lane 16) which was absent if nonimmune serum was used as a control (lane 15).

Phosphorylation of the SSR could also be demonstrated in a cell-free system (Fig. 5, lanes 1-14). If crude microsomal membranes were incubated with $\left[\gamma^{32}\right]$ ATP many labelled 


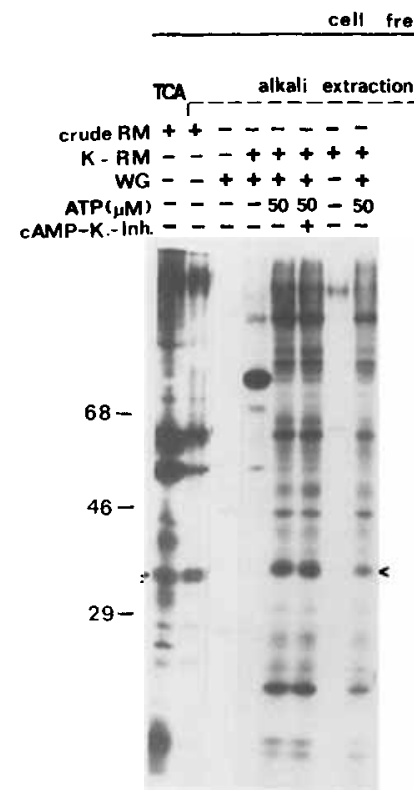

$\begin{array}{llllllll}1 & 2 & 3 & 4 & 5 & 6 & 7 & 8\end{array}$

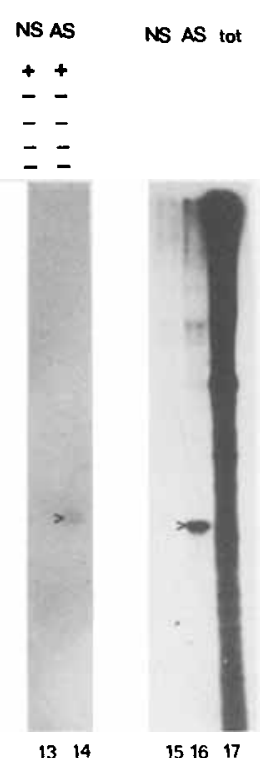

$910 \div 12$

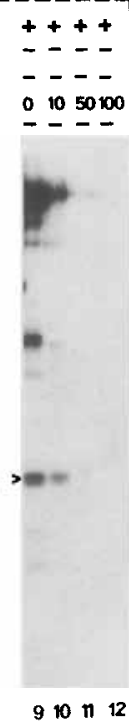

1314
MDCK colls

AS tot
Fig. 5. Phosphorylation of the SSR. Phosphorylation of the SSR was carried out either in a cell-free system with $\left[\gamma_{-}{ }^{32}\right.$ P]ATP (lanes $1-14$ ) or in intact MDCK cells with [ ${ }^{32}$ P]phosphate (lanes 15-17). Where indicated, immunoprecipitation with antiserum against SSR (AS) or with non-immune serum (NS) was carried out. The other samples were analyzed either after precipitation with trichloroacetic acid (TCA) or after alkaline extraction of the membranes. In the in vitro reactions, either crude microsomes (crude RM) or salt-washed microsomes (K-RM) were used. Wheat germ postribosomal supernatant (WG), a specific inhibitor of the cAMP-dependent protein kinase (cAMP-K.Inh.) and unlabelled ATP were added as indicated. The arrow head indicates the position of SSR

bands could be seen (Fig. 5, lane 1), some of which, including that of SSR, were resistent to alkaline extraction (lane 2). The identity of the labelled SSR was proven by immunoprecipitation (cf. Fig. 5, lanes 13 and 14). Low concentrations of unlabelled ATP were sufficient to abolish the phosphorylation (Fig. 5, lanes 9-12). The kinase responsible for the phosphorylation appears to be peripherally bound to the microsomes since extensive washing with high salt removed the activity (Fig. 5, lane 7). The SSR in thouroughly washed microsomes could be phosphorylated by a kinase present in wheat germ postribosomal supernatant (Fig. 5, lane 8) although the band was less prominent than in experiments with crude microsomes. Some of the labelled bands appeared to be identical but there were also differences in the overall pattern (e.g. Fig. 5, cf. lanes 8 and 9), indicating that different kinases are involved. If no unlabelled ATP was added in experiments with wheat germ extract, a major band was seen but phosphorylated SSR could not be detected (Fig. 5, lane 4). As expected, no labelled bands were seen in the alkaline extracted pellet in the absence of membranes (Fig. 5, lane 3). The phosphate in the SSR was found in the cytosolic tail; all the label was lost after proteolysis. Most of the phosphate was attached to serine (data not shown). Phosphorylation could also be observed with $\left[{ }^{32} \mathrm{P}\right] \mathrm{GTP}$ but it cannot be excluded as yet that transfer of the label to ATP (or vice versa in the experiments with labelled ATP) had occurred.

Phosphorylation was not catalyzed by the cAMP-dependent kinase since a specific inhibitor [30] did not have any effect (Fig. 5, cf. lanes 5 and 6). Also, neither isolated cAMP- dependent kinase phosphroylated the SSR nor did EGTA inhibit phosphorylation by wheat germ extract, indicating that the calmodulin-dependent kinase also was not involved (data not shown).

\section{The SSR is located in the ER}

Previous data suggested the ER localization of the SSR on the basis of its abundance in microsomal preparations from dog pancreas. This conclusion could be confirmed by immunofluorescence microscopy using specific antibodies (Fig. 6). The figure shows an ER-typical, network-like staining of CV-1 cells transiently expressing the SSR. A similar staining pattern, although much weaker, may be seen in neighbouring cells with a low expression level.

\section{DISCUSSION}

We have determined the primary structure of the SSR, an essential component of the protein translocation complex of the ER membrane. The amino acid sequence did not show any apparent homology to any of the sequences in the EMBL Sequence Data Library (release 19, May 1989). Also, there is no similarity to the $54-\mathrm{kDa}$ polypeptide component of the SRP $[31,32]$ which interacts with signal sequences $[2,3]$. Thus although the signal sequence of nascent preprolactin is close to the SSR during translocation, a specific binding in the same way as suggested for the $54-\mathrm{kDa}$ polypeptide appears to be unlikely. The photocrosslinking of the signal sequence does not occur with the cytoplasmic domain of the SSR [10], in agreement with the fact that its sequence is short and highly charged. The possibility remains that other portion(s) of the SSR have an affinity for signal sequences.

Our belief that SSR is part of a translocation complex appears at variance with the fact that only one classical membrane-spanning segment could be identified rather than several amphipathic helices as is typical for ion and electron channels [12]. However, one may expect a protein-translocating tunnel to be quite different from the rather rigid structures produced by the association of amphipathic helices. It may be assumed to be more flexible since preprolactin can be translocated across the ER membrane even if bulky biotin groups are attached to the side chains of its lysines [33]. For mitochondria evidence exists that even branched, crosslinked proteins and proteins linked to oligonucleotides are able to cross membranes [34].

The membrane topology of the SSR seems to be such that the hydrophobic segment comprising residues $207-230$ spans the membrane with its $\mathrm{N}$-terminus located in the lumen of the ER and its C-terminus in the cytoplasm. The role of the remarkable charge distribution, with the lumenal portion negatively charged and the cytoplasmic portion positively charged, is unclear as yet. It may be in the build up of a local membrane potential. For protein translocation across the cytoplasmic membrane in Escherichia coli and for protein import into mitochondria the function of a bulk membrane potential has been demonstrated $[35,36]$. Although such a potential is probably not required for protein translocation across the ER membrane since ionophores have no effect $[37,38]$ (our unpublished results), a local potential could conceivably be involved.

The structure of the SSR suggests that it cannot be the only component of a presumed translocation complex. The fact that two polypeptides were coimmunoprecipitated with 


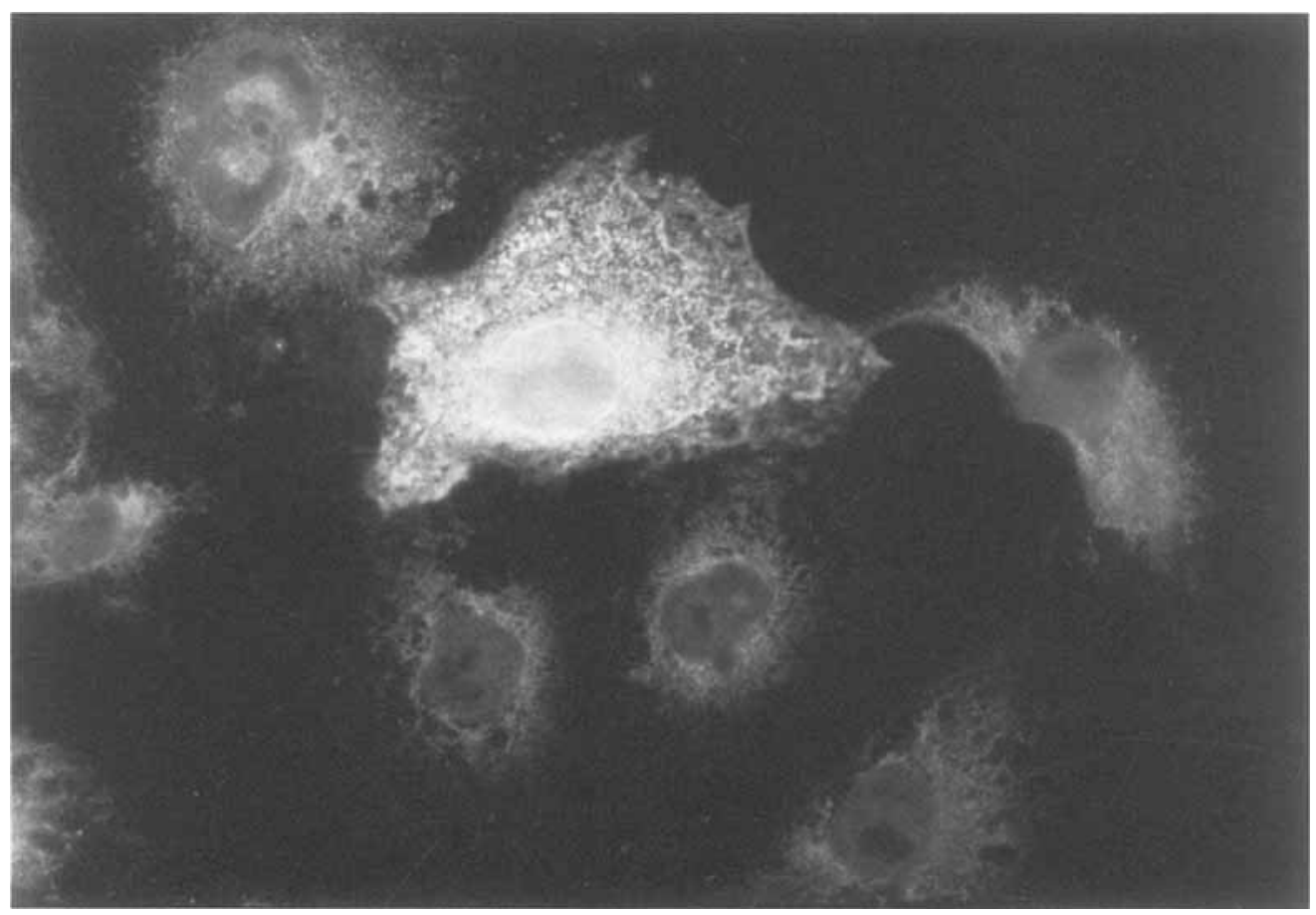

Fig. 6. Cellular localization of the SSR analyzed by immunofluorescence microscopy. CV-1 cells were transfected with a clone expressing SSR under a simian virus 40 promoter. The localization of SSR was analyzed by immunofluorescence microscopy using antibodies to the SSR and tetramethylrhodamine-isothiocyanate-labelled second antibodies

SSR antibodies suggests that indeed other components are tightly bound. One of them, a $\approx 22-\mathrm{kDa}$ glycoprotein, has been purified recently and shown to form a stable complex with the SSR (D. Goerlich et al., unpublished data). Thus, SSR may well be a component of a larger complex.

We have also found that SSR is phosphorylated in its cytoplasmic tail. It is tempting to speculate that phosphorylation regulates the translocation process. For example, phosphorylation or dephosphorylation may induce the formation or the opening of the tunnel. Since wheat germ contains a SSR kinase, it appears possible that phosphorylation occurs in the in vitro translation/translocation system. However, further work, including purification of the kinase, is required to prove a role for a phosphorylation cycle in the translocation process.

It is interesting that the membrane insertion of the SSR depends on the function of the SRP. This is in contrast to the biosynthesis of another membrane component of the translocation apparatus, the $\alpha$-subunit of the SRP receptor, which is independent of SRP $[39,40]$. Our results show that synthesis of a translocation component depends on the prior existence of a translocation system (a specification of the old statement of R. Virchow: 'omnis cellula e cellula' [41]).

We thank H. Gausepohl and A. Bosserhoff (EMBL, Heidelberg) for the synthesis of a peptide and for help in amino acid sequencing, respectively. We are grateful to Drs $\mathrm{R}$. Kraft and A. Otto (Zentralinstitut für Molekularbiologie, Berlin-Buch) for confirming some of the amino acid sequences, to Dr H. Schunck for help in labelling cells with $\left[{ }^{32} \mathrm{P}\right]$ phosphate, to Dr S. Bartel for the supply of inhibitor of the cAMP-dependent protein kinase, to Dr M. Wiedmann for helpful comments, and to Prof. S. Rapoport for critical reading of the manuscript.

\section{REFERENCES}

1. Walter, P. \& Blobel, G. (1981) J. Cell Biol. 91, 557-561.

2. Kurzchalia, T. V., Wiedmann, M., Girshovich, A. S., Bochkareva, E. S., Bielka, H. \& Rapoport, T. A. (1986) Nature 320 , $634-636$.

3. Krieg, U. C., Walter, P. \& Johnson, A. E. (1986) Proc. Natl Acad. Sci. USA 83, 8604-8608.

4. Gilmore, R., Walter, P.\& Blobel, G. (1982) J. Cell Biol. 95, 470477.

5. Meyer, D. I., Krause, E. \& Dobberstein, B. (1982) Nature 297 , $647-650$.

6. Connolly, T. \& Gilmore, R. (1989) Cell 57, 599-610.

7. Gilmore, R. \& Blobel, G. (1983) Cell 35, 677-685.

8. Wiedmann, M., Kurzchalia, T. V., Bielka, H. \& Rapoport, T. A. (1987) J. Cell Biol. 104, $201-208$.

9. Wiedmann, M., Kurzchalia, T. V., Hartmann, E. \& Rapoport, T. (1987) Nature 328, 830-833.

10. Wiedmann, M., Goerlich, D., Hartmann, E., Kurzchalia, T. V.\& Rapoport, T. A. (1989) FEBS Lett 257, 263-268.

11. Hartmann, E., Wiedmann, M. \& Rapoport, T. A. (1989) EMBO J. $8,2225-2229$.

12. Lodish, H. F. (1988) Trends Biochem. Sci. 13, 332-334

13. Aebersold, R. H., Leavitt, J., Saavedra, R. A., Hood, L. E. \& Kent, S. B. H. (1987) Proc. Natl Acad. Sci. USA 84, 69706974.

14. Haymerle, H., Herz, J., Bressan, G., Frank, R. \& Stanley, K. K. (1986) Nucleic Acids Res 14, 8615-8624.

15. Maniatis, T., Fritsch, E. F. \& Sambrook, J. (1982) Molecular cloning: a laboratory manual, Cold Spring Harbour Laboratory, Cold Spring Harbour, New York.

16. Stanley, K. K. \& Luzio, J. P. (1984) EMBO J. 3, $1429-1433$.

17. Melton, D. A., Krieg, P. A., Rebagliati, M. K., Maniatis, T., Zinn, K., Green, M. K. (1984) Nucleic Acids Res. 12, 70357070 .

18. Walter, P. \& Blobel, G. (1983) Methods Enzymol. 96, 84-93.

19. Walter, P. \& Blobel, G. (1983) Methods Enzymol. 96, 682-691.

20. Lau, J. T. Y., Welply, J. K., Shenbagamurthi, P., Naider, F. \& Lennarz, W. J. (1983) J. Biol. Chem. 258, 15255-15260. 
21. Huylebroeck, D., Maertens, G., Verhoeyen, M., Lopez, C., Raeymakers, A., Min Jou, W. \& Fiers, W. (1988) Gene 66, $163-181$

22. Glover, D. M. (1985) DNA cloning, a practical approach, vol. 2, IRL Press, Oxford, Washington DC.

23. Laemmli, U. K. (1970) Nature 227, 680-685.

24. Lauffer, L., Garcia, P. D., Harkins, R. N., Coussens, L., Ullrich, A. \& Walter, P. (1985) Nature 318, 334-338.

25. Kozak, M. (1989) J. Cell Biol. 108, 229-241.

26. Kyte, J. \& Doolittle, R. F. (1982) J. Mol. Biol. 157, $105-132$.

27. Eisenberg, D., Schwarz, E., Komaromy, M.\& Wall, R. (1984) $J$. Mol. Biol. 179, 125-142.

28. Rapoport, T. A. (1986) CRC Crit. Rev. Biochem. 20, 73-137.

29. von Heijne, G. (1986) Nucleic Acids Res. 14, 4683-4690.

30. Demaille, J. G., Peters, K. A. \& Fischer, E. H. (1977) Biochemistry 16, 3080-3086.

31. Roemisch, K., Wegg. J., Herz, J., Prehn, S., Frank, R., Vingron, M. \& Dobberstein, B. (1989) Natue 340, 478-482.

32. Bernstein, H. D., Poritz, M. A., Strub, K., Hoben, P. J., Brenner, S. \& Walter, P. (1989) Nature 340, 482-486.
33. Kurzchalia, T. V., Wiedmann, M., Breter, H., Zimmermann, W., Bauschke, E. \& Rapoport, T. A. (1988) Eur. J. Biochem. 172, $663-668$.

34. Vestweber, D. \& Schatz, G. (1989) Nature 338, 170-172.

35. Date, T., Goodman, J. M. \& Wickner, W. T. (1980) Proc. Natl Acad. Sci. USA 77, 4669-4673.

36. Schleyer, M., Schmidt, B. \& Neupert, W. (1982) Eur. J. Biochem. $125,109-116$.

37. Waters, M. G. \& Blobel, G. (1986) J. Cell. Biol. 102, $1543-$ 1550.

38. Mueckler, M. \& Lodish, H. F. (1986) Nature 322, 549-552.

39. Hortsch, M. \& Meyer, D. I. (1988) Biochim. Biophys. Res. Commun. 150, 111-117.

40. Andrews, D. W., Lauffer, L., Walter, P. \& Lingappa, V. R. (1989) J. Cell. Biol. 108, 797-810.

41. Virchow, R. (1855) Arch. Pathol. Anat. Physiol. Klin. Med. 8, 3-39. 